\title{
A bibliometric assessment of energy research in
}

AUTHOR:

Anastassios Pouris ${ }^{1}$

\section{AFFILIATION:}

${ }^{1}$ Institute of Technological

Innovation, University of Pretoria,

Pretoria, South Africa

\section{CORRESPONDENCE TO:}

Anastassios Pouris

EMAIL:

apouris@icon.co.za

\section{DATES:}

Received: 01 Apr. 2016

Revised: 26 June 2016

Accepted: 02 Aug. 2016

\section{KEYWORDS:}

scientometrics; state of field; fuels research; indicators

\section{HOW TO CITE:}

Pouris A. A bibliometric assessment of energy research in South Africa. S Afr J Sci. 2016; 112(11/12), Art. \#2016-0054, 8 pages. http://dx.doi.org/10.17159/ sajs.2016/20160054

\section{ARTICLE INCLUDES: \\ $\times$ Supplementary material \\ $\times$ Data set}

FUNDING:

South African Department of Science and Technology (c) 2016. The Author(s). Published under a Creative Commons Attribution Licence.
The results of an effort to identify the performance of energy and fuels research in South Africa during the most recent period (2003-2013) are reported. Bibliometric approaches have been employed in order to assess the field of energy research. Energy research was identified to be improving over time, albeit from a small basis. The field appears to equally emphasise fossil and renewable energy research. Similarly, universities were identified to be producing a subcritical number of energy articles in comparison with international organisations. The relatively small activity in the energy field appears to affect the international collaboration of the field, which is well below the national average. International comparisons in terms of articles per GWH of electricity produced and articles per million population show that South Africa should increase substantially its effort in the field in order to be comparable with other countries.

\section{Significance:}

- This article makes a unique contribution in scientometrics to the field of energy research in South Africa which, given its multidisciplinary nature, is a generally neglected field of study in South Africa.

\section{Introduction}

Monitoring and assessment are integral parts of science, technology and innovation policy. Decision-makers need to know the performance of the various research disciplines so they can make intelligent decisions in the allocation of scarce resources. Historically, monitoring and assessment relied on expert opinions. Nowadays such assessments are based on quantitative information.

One of the most efficient and objective methods of assessing research and innovation performance is through bibliometric indicators. Bibliometric analysis, the quantitative study of the research system, is based mainly on publication indicators. In bibliometrics, the number of publications in a field is considered to be an indicator of research activity and the number of citations as an indicator of impact.

Bibliometric assessments have a number of advantages. For example, they are repeatable and verifiable exercises. They are not dependent on the choice of experts/peer reviewers or on their opinions which may vary. Their most important advantage is probably that they allow comparisons among different scientific disciplines and different countries. Both types of comparisons are not possible through peer-review approaches as it is almost impossible to find peers with expertise in different scientific fields and knowledge of the research systems in different countries.

Within this context, a number of South African related assessments have appeared in the open and grey literature recently. ${ }^{1-3}$ There are limited mapping and comparative assessments in the field of energy nationally and internationally. Relevant literature includes Vlachy ${ }^{4}$, Pouris et al. ${ }^{5}$, Uzun ${ }^{6}$ and Kostoff et al. ${ }^{7}$. As we have argued previously:
This lack of research activity may have a number of adverse consequences for the economy. For example, it can be argued that the lack of expertise and independent advice (e.g. in the country's universities) may be partially the cause of the recent failure of Eskom to meet electricity demand in the country. ${ }^{8(p .2)}$

Similarly, the current debate related to the country's nuclear energy needs may have been better informed from independent, academic investigations.

The objective of this investigation is to assess the field of energy research in the country. More specifically, the objective is to assess the performance of the field during the most recent period from 2003 to 2013 to: (1) identify the sub-disciplines (e.g. fossil fuel research vis-a-vis renewable energies) emphasised in the country; (2) compare the country's performance with those of other countries and (3) elaborate on relevant research policy issues. These issues can guide policy in a number of domains. For example, the number of research publications produced is related to the expertise and financial resources available in the field in the country. Hence, one question that can be answered is whether the field is adequately supported. Similarly, the determination of sub-disciplines in which research is published can identify areas of inadequate support or emphasis. Comparisons of research outputs at institutional level can provide insights on the efficacy of existing instruments, approaches, etc.

\section{Methodology}

Bibliometric assessments require the availability of a database that covers adequately the subject under investigation. The Thomson Reuters databases - Science Citation Index Expanded, Social Sciences Citation Index and Arts and Humanities Citation Index - are the most often used for these types of investigations.

These databases combined cover comprehensively the most prestigious journals in the world in all fields of research and constitute a unique information platform for this objective. The most important advantage of these journals is that they constitute the most important (in terms of impact) journals in the world. Furthermore, the Thomson Reuters databases provide the corporate addresses of all co-authors in an article, and hence comprehensive coverage is possible. 
In South Africa, the Department of Higher Education has approved the journals indexed by the Thomson Reuters databases for subsidy purposes; therefore universities receive approximately ZAR120 000 for each article published in one of these journals and provide incentives to their researchers to publish in such journals. Consequently, it is expected that the databases will cover not only the most important South African energy-related research but also the majority.

Two approaches were considered for the extraction of the relevant research literature: phrase-based query and journal-title-based query.

Thomson Reuters assigns the indexed journals to scientific categories. The energy-related journals are grouped under the title 'Energy and Fuels'. This group includes 138 journals. These journals can be considered as consisting of the 'core' journals of the field of energy in the Bradfordian sense. ${ }^{9}$ It is emphasised that there are articles related to energy that are not published in the core journals. However, the most important and highest impact energy literature will be that published in the core journals, and hence this analysis aims to identify South Africa's contribution in the core energy literature. Keyword-based searches were used for the identification of research related to different types of primary energy (e.g. fossil and alternative energy; energy converters).

The platform was interrogated for the identification of South African authors publishing in the field of 'Energy and Fuels' during the period 2003-2013. The end of the period was chosen as 2013 as this was the most recent year with complete data. This investigation was initiated during 2014 and was completed during 2015.

The extracted information was analysed in order to identify trends over time; relative performance in comparison with other scientific disciplines in the country; research emphases to various primary sources of energy and technologies; prolific publishing organisations; co-authorship patterns with other countries and institutions; and relative performance vis-à-vis a set of comparator countries (i.e. Australia, Canada, New Zealand, Brazil and Russia). The comparator countries were chosen among those used for benchmarking exercises by the South African Department of Science and Technology.

\section{Energy research in South Africa}

Analysis of the core energy literature identified that 752 articles with at least one South African address appeared in the database during the 2003-2013 period. This figure represents $66.4 \%$ of all documents captured in the database (proceeding papers; meeting abstracts; editorial material, etc). A focus on articles prevents double counting, as a conference paper may also be published as a journal article.

Figure 1 shows the annual number of South African publications in the core energy literature for the period 2003-2013. It becomes apparent that South Africa's contribution to core energy literature is showing an increasing trend. The number of South African articles has grown from 24 during 2003 to 145 during 2013. It should be emphasised that this nominal increase takes place in an environment of increasing national research publications in general and international energy articles in particular.

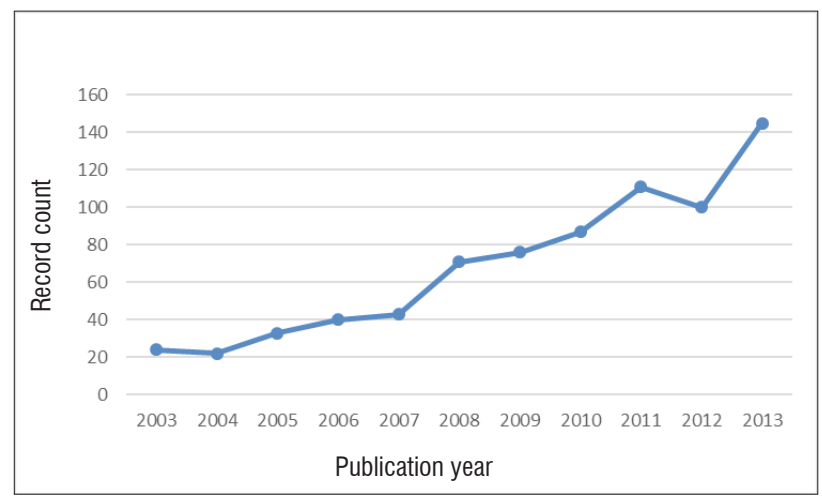

Figure 1: The number of Energy and Fuels articles from South Africa in the period 2003-2013
Figure 2 shows the percentage of energy articles of the country's total publications. The percentage of energy articles increased faster than those of the other scientific disciplines in the country during the last decade. Energy and Fuels articles increased from about $0.6 \%$ in the beginning of the 2000s to about $1 \%$ during the end of the period. This increase is partially the result of Thomson Reuters increasing the coverage of energy journals. Figure 3 makes this point. Even though the absolute number of energy articles increased, the country's share in the world energy publications has been static since 2008 .

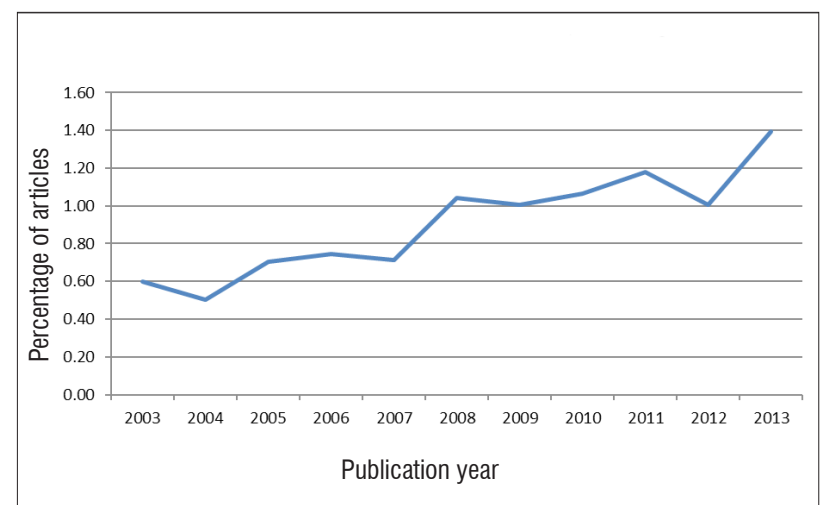

Figure 2: Percentage of energy-related articles relative to the total number of articles from South Africa in the period 2003-2013.

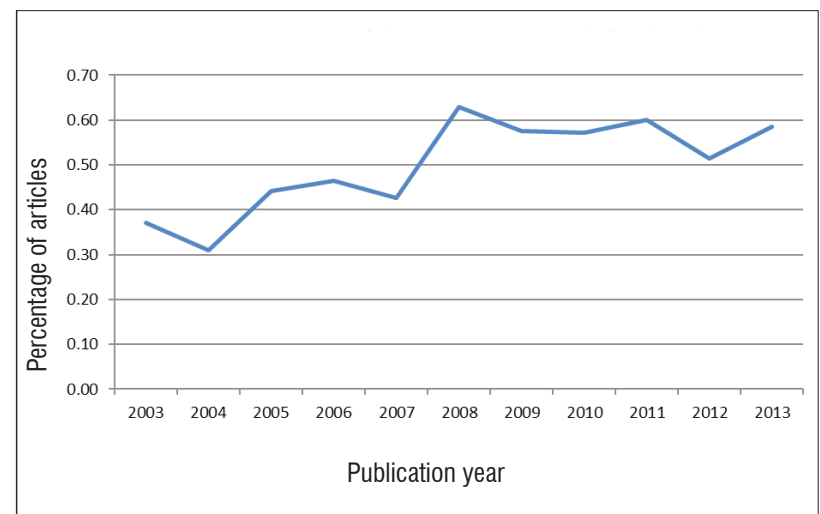

Figure 3: Percentage of energy-related articles from South Africa relative to the total number of articles in the field during the period 2003-2013.

Figure 3 shows the percentage of South African Energy and Fuels publications within the total field. The relevant share increased from about $0.4 \%$ at the beginning of the period to about $0.6 \%$ at the end of the period. However, the trend has been static since 2008 .

Table 1 shows the number of articles produced by South African researchers according to various research areas during the 20032013 period. The table reveals a priority ranking. Environmental Sciences and Ecology and Chemistry are on top of the list with more than 5000 articles over the period. Energy and Fuels appears 47th in the list with 752 articles. It is interesting to note that Water Resources - another multidisciplinary field - appears 22nd in the list. Jacobs et al. ${ }^{2}$ argued that the existence of a funding body like the Water Research Commission is the underlying factor for the good performance of this research area. While there is an energy-related agency in the country (Sanedi), it suffers from limited financial support by the government. Similarly, other organisations like Eskom and the National Research Foundation provide limited support for energy research. Furthermore, changes in the various national incentives (e.g. THRIP) are expected to have an adverse effect on energy research publications. 
Table 1: Number of research articles from South Africa in the period 2003-2013 according to research area

\begin{tabular}{|c|c|c|}
\hline Rank & Research area & Record count \\
\hline 1 & Environmental Sciences Ecology & 5326 \\
\hline 2 & Chemistry & 5099 \\
\hline 3 & Engineering & 4644 \\
\hline 4 & Physics & 4037 \\
\hline 5 & Plant Sciences & 3046 \\
\hline 6 & Mathematics & 2879 \\
\hline 7 & Science Technology Other Topics & 2588 \\
\hline 8 & Agriculture & 2566 \\
\hline 9 & Zoology & 2541 \\
\hline 10 & Public Environmental Occupational Health & 2431 \\
\hline 11 & Infectious Diseases & 2407 \\
\hline 12 & Astronomy Astrophysics & 2108 \\
\hline 13 & Psychology & 2102 \\
\hline 14 & Geology & 2072 \\
\hline 15 & Business Economics & 2072 \\
\hline 16 & Immunology & 1998 \\
\hline 17 & Biochemistry Molecular Biology & 1979 \\
\hline 18 & Material Science & 1894 \\
\hline 19 & Education Educational Research & 1828 \\
\hline 20 & Pharmacology Pharmacy & 1812 \\
\hline 21 & General Internal Medicine & 1657 \\
\hline 22 & Water Resources & 1618 \\
\hline 23 & Microbiology & 1596 \\
\hline 24 & Biotechnology Applied Microbiology & 1581 \\
\hline 25 & Veterinary Sciences & 1579 \\
\hline 26 & Marine Freshwater Biology & 1545 \\
\hline 27 & Religion & 1268 \\
\hline 28 & Computer Science & 1213 \\
\hline 29 & Entomology & 1198 \\
\hline 30 & Food Science Technology & 1167 \\
\hline 31 & Virology & 1121 \\
\hline 32 & Crystallography & 1070 \\
\hline 33 & Evolutionary Biology & 1013 \\
\hline 34 & Mining Mineral Processing & 948 \\
\hline 35 & Government Law & 935 \\
\hline 36 & Surgery & 924 \\
\hline 37 & Biodiversity Conservation & 920 \\
\hline 38 & Metallurgy Metallurgical Engineering & 908 \\
\hline 39 & Neurosciences Neurology & 896 \\
\hline 40 & Genetics Heredity & 889 \\
\hline
\end{tabular}




\begin{tabular}{|c|c|c|}
\hline Rank & Research area & Record count \\
\hline 41 & Social Sciences Other Topics & 877 \\
\hline 42 & Paediatrics & 864 \\
\hline 43 & Respiratory System & 807 \\
\hline 44 & Meteorology Atmospheric Sciences & 781 \\
\hline 45 & Linguistics & 760 \\
\hline 46 & Health Care Sciences Services & 757 \\
\hline 47 & Energy Fuels & 752 \\
\hline 48 & Life Sciences Biomedicine Other Topics & 744 \\
\hline 49 & Public Administration & 743 \\
\hline 50 & Psychiatry & 738 \\
\hline 51 & Cardiovascular System Cardiology & 732 \\
\hline 52 & Geochemistry Geophysics & 699 \\
\hline
\end{tabular}

Table 2 shows the distribution of the South African Energy and Fuels publications to different scientific specialties. Articles are allocated to categories according to the journal in which they are published. Journals are categorised by Thomson Reuters' staff and may belong to one or more categories. The distribution of articles to disciplines shows the linkages of Energy and Fuels to other research areas. Approximately 40\% of Energy and Fuels articles are based on Engineering and 12\% on Chemistry. In comparison with worldwide emphases in the field, South Africa pays less attention to electrochemistry ( $9.7 \%$ versus $17 \%$ worldwide), biotechnology (5.8\% versus $9.6 \%$ ) and agriculture (5.1\% versus $9 \%$ ).

An important component of scientometrics is the capability to identify the subfields and/or technologies constituting a research field.

Table 2: Distribution to research area of Energy and Fuels research articles from South Africa in the period 2003-2013

\begin{tabular}{l|c}
\hline \hline \multicolumn{1}{c|}{ Research area } & Record count \\
\hline Energy Fuels & 752 \\
\hline Engineering & 299 \\
\hline Chemistry & 93 \\
\hline Electrochemistry & 73 \\
\hline Environmental Sciences Ecology & 69 \\
\hline Construction Building Technology & 65 \\
\hline Thermodynamics & 57 \\
\hline Biotechnology Applied Microbiology & 44 \\
\hline Agriculture & 39 \\
\hline Physics & 34 \\
\hline Mechanics & 25 \\
\hline Materials Science & 23 \\
\hline Mining Mineral Processing & 9 \\
\hline Geology & 8 \\
\hline Optics & 5 \\
\hline Nuclear Science Technology & 9 \\
\hline
\end{tabular}

Research fields are composed of many subfields and technologies which are constantly developing or becoming obsolete. The identification of these emphases is of importance for policymakers who need to guide the system according to their priorities and for researchers who need to know fledgling technologies which will shape the discipline in the future. It is also critical to emphasise that the composition of the research landscape is dynamic.

Researchers working in the field develop approaches in order to extract the relevant information from bibliometric and patent databases. ${ }^{7,10}$

Table 3 presents the classification of the South African articles in the research area Energy and Fuels. For the fossil fuels, the keywords used were: fossil; coal; oil; gas; gasification; liquefaction; alkylation; desulfurisation; electrocatalysis; liquid fuel; fluidised bed; emission; char; ash; combustion; pyrolysis; catalysis; incineration; engine; turbine. Among the Energy and Fuels articles, 237 articles had in their titles one or more of the keywords characterising fossil fuels and energy.

Articles related to renewable energy were identified by searching in their titles for at least one of the following keywords: solar; hydrogen; wind; geo*; bio*; hydro power; photovoltaic; tidal; waste fuel; fermentation; microbial desulfurisation; biosulfurisation; thermal decomposition; biodegradation; biomass gasification; water gasification; renewable. A total of 211 articles was identified. The number of renewable energy related articles increased from a handful in the beginning of the period to approximately 30 articles per annum during the end of the period.

The keywords: fuel cell; photovoltaic; solar collector; electrode; electrolyte; and membrane were used to search for direct electric converters and 66 articles related to such research were identified.

In addition, 85 energy-related articles were published in social science journals during the 2003-2013 period (Table 3).

Table 4 shows the frequency of appearance of certain terms in the list of topics of the South African energy and fuels research articles.

The topics related to 'efficiency' have the highest number of articles in the list (177). Figure 4 shows the increase in the number of energy efficiency articles during the period. 'Coal' follows with 135 entries; 'electricity' with 119 and 'oil and liquid fuels' with 113. Among the renewable energies, 'solar' and 'hydrogen' attract the most entries (98 and 73 , respectively). It should be mentioned that 'solar', 'hydrogen' and 'biomass' have the common characteristic that they are not site specific. In contrast, 'wind' and 'geothermal' are constrained to geographical areas with favourable operating environments. 
Table 3: Classification into broad categories of Energy and Fuels articles from South Africa in the period 2003-2013

\begin{tabular}{l|c|c}
\hline \hline \multicolumn{1}{c|}{ Category } & $\begin{array}{c}\text { Number of South } \\
\text { African articles }\end{array}$ & $\begin{array}{c}\text { Share of South African } \\
\text { total }\end{array}$ \\
\hline Fossil & 237 & $31.5 \%$ \\
\hline Renewable & 211 & $28.0 \%$ \\
\hline Social Sciences & 85 & $11.3 \%$ \\
\hline Direct Energy Converters & 66 & $8.7 \%$ \\
\hline Total Energy and Fuels & 752 & $100.0 \%$ \\
\hline
\end{tabular}

Table 4: Number of Energy and Fuel articles from South Africa in the period 2003-2013 according to specific topics

\begin{tabular}{l|c}
\hline \hline \multicolumn{1}{c|}{ Topic } & $\begin{array}{c}\text { Number of } \\
\text { articles }\end{array}$ \\
\hline Coal & 135 \\
\hline Electricity & 119 \\
\hline Oil or liquid fuels & 113 \\
\hline Natural gas & 19 \\
\hline Solar & 98 \\
\hline Hydrogen & 73 \\
\hline Biomas* & 53 \\
\hline Wind & 34 \\
\hline Hydrop* & 12 \\
\hline Geoth* & 2 \\
\hline Thermal insulation; lighting; double glazing; water heating; & 59 \\
\hline space heating & 177 \\
\hline Efficien*
\end{tabular}

*indicates all forms of the word

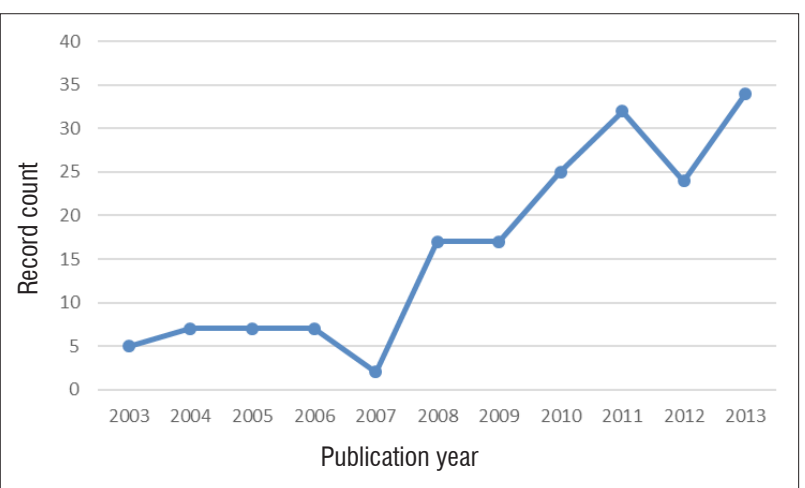

Figure 4: Growth in the number of Energy and Fuels articles related to efficiency from South Africa in the period 2003-2013.

Table 5 shows the South African organisations that are producing the majority of core energy and fuels literature. The Universities of Cape Town, Stellenbosch and Pretoria are on top of the list. Three divisions of Sasol also appear on the list. It should be noted that even the top institutions in the country produce less than 10 articles per year each on average during the period. The small number of publications makes the rankings volatile; and just a handful of publications could alter the rankings.

Table 5: South African organisations producing Energy and Fuels articles during the period 2003-2013

\begin{tabular}{l|c}
\hline \multicolumn{1}{c|}{ Organisation } & Record count \\
\hline University of Cape Town & 107 \\
\hline Stellenbosch University & 100 \\
\hline University of Pretoria & 76 \\
\hline North West University & 69 \\
\hline University of the Witwatersrand & 66 \\
\hline University of KwaZulu-Natal & 66 \\
\hline Council for Scientific and Industrial Research & 59 \\
\hline University of the Western Cape & 51 \\
\hline Tshwane University of Technology & 46 \\
\hline SASOL Technology PTY LTD & 27 \\
\hline University of Johannesburg & 26 \\
\hline SASOL Technology RES DEV & 26 \\
\hline Nelson Mandela Metropolitan University & 24 \\
\hline Cape Peninsula University of Technology & 19 \\
\hline SASOL Technology & 16 \\
\hline
\end{tabular}

The top five institutions produce more than $50 \%$ of the country's contribution to core energy and fuels literature. This result may be identified as a considerable dispersion, as a number of other scientific disciplines are concentrated in only one or two institutions in the country. For example, in the field of veterinary medicine/animal health, the University of Pretoria produces $61.68 \%$ of the country's research publications. The University of Pretoria also produces $49.15 \%$ of the country's publications in metallurgy and $46.96 \%$ in engineering mathematics. ${ }^{11}$ As argued previously, it appears that political equity considerations in the country spill over in the research domain as well. To repeat it here, the issue is of particular developmental and research policy importance. Can a country leapfrog its science and innovation system to catch up with the rest of the world and compete internationally through a 'distributed' approach or should it concentrate its limited scientific expertise to a small number of focused research centres?

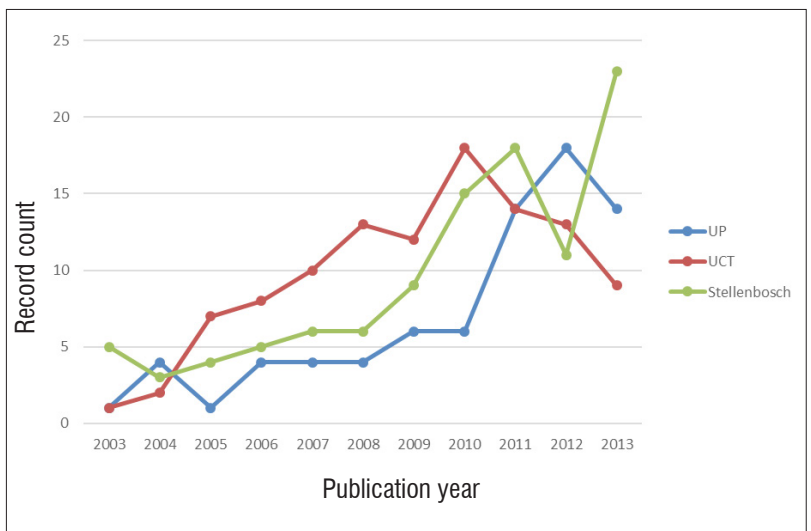

Figure 5: The number of Energy and Fuels articles produced by the Universities of Cape Town (UCT) and Pretoria (UP) and Stellenbosch University during the period 2003-2013. 
Figure 5 shows the number of Energy and Fuels articles produced by the country's most prolific organisations. Again the limitation of a small number of publications should be emphasised.

Table 6 shows the number of Energy and Fuels articles produced by the most prolific organisations in India, Australia, Canada and South Africa. The South African organisations would need to increase their relevant research activity in the field fivefold in order to be comparable with those in the other countries.

Table 6: Prolific numbers of Energy and Fuels articles produced by organisations in India, Canada, Australia and South Africa during 2003-2013

\begin{tabular}{l|l|c}
\hline \hline \multicolumn{1}{c|}{ Organisations } & \multicolumn{1}{c|}{ Country } & $\begin{array}{c}\text { Record } \\
\text { count }\end{array}$ \\
\hline India Institute of Technology & India & 1560 \\
\hline $\begin{array}{l}\text { Council of Scientific and Industrial Research } \\
\text { India }\end{array}$ & India & 1105 \\
\hline University of New South Wales & Australia & 566 \\
\hline $\begin{array}{l}\text { Commonwealth Scientific Industrial Research } \\
\text { Organisation }\end{array}$ & Australia & 440 \\
\hline University of Queensland & Australia & 348 \\
\hline Western University of Western Ontario & Canada & 575 \\
\hline University of Calgary & Canada & 672 \\
\hline University of Alberta & Canada & 589 \\
\hline University of Waterloo & Canada & 435 \\
\hline University of Cape Town & South Africa & 103 \\
\hline Stellenbosch University & South Africa & 100 \\
\hline University of Pretoria & South Africa & 76 \\
\hline
\end{tabular}

Table 7: Countries collaborating with South Africa in Energy and Fuels articles

\begin{tabular}{l|c|c}
\hline \hline \multicolumn{1}{c|}{ Country } & Record count & \% of 752 \\
\hline South Africa & 752 & \\
\hline USA & 59 & $7.846 \%$ \\
\hline France & 28 & $3.723 \%$ \\
\hline People's Republic of China & 25 & $3.324 \%$ \\
\hline England & 25 & $3.324 \%$ \\
\hline Iran & 20 & $2.660 \%$ \\
\hline India & 20 & $2.660 \%$ \\
\hline Canada & 18 & $2.397 \%$ \\
\hline Nigeria & 15 & $1.995 \%$ \\
\hline Netherlands & 13 & $1.729 \%$ \\
\hline Germany & 13 & $1.729 \%$ \\
\hline Australia & 13 & $1.729 \%$ \\
\hline Malaysia & 8 & $1.064 \%$ \\
\hline Zimbabwe & 6 & $0.798 \%$ \\
\hline
\end{tabular}

Table 8: Country ranking according to number of Energy and Fuels articles in 2003-2013

\begin{tabular}{|c|c|c|}
\hline Rank & Country & Record count \\
\hline 1 & People's Republic of China & 33971 \\
\hline 2 & USA & 24760 \\
\hline 3 & Japan & 6280 \\
\hline 4 & Germany & 6078 \\
\hline 5 & India & 5721 \\
\hline 6 & Canada & 5307 \\
\hline 7 & England & 5120 \\
\hline 8 & South Korea & 4722 \\
\hline 9 & Spain & 4714 \\
\hline 10 & France & 4326 \\
\hline 11 & Italy & 4161 \\
\hline 12 & Australia & 3579 \\
\hline 13 & Taiwan & 3459 \\
\hline 14 & Iran & 3127 \\
\hline 15 & Turkey & 2928 \\
\hline 16 & Netherlands & 2088 \\
\hline 17 & Brazil & 2077 \\
\hline 18 & Sweden & 1988 \\
\hline 19 & Russia & 1913 \\
\hline 20 & Malaysia & 1842 \\
\hline 21 & Denmark & 1487 \\
\hline 22 & Norway & 1341 \\
\hline 23 & Poland & 1308 \\
\hline 24 & Greece & 1267 \\
\hline 25 & Czech Republic & 1241 \\
\hline 26 & Switzerland & 1232 \\
\hline 27 & Thailand & 1159 \\
\hline 28 & Mexico & 1120 \\
\hline 29 & Singapore & 1099 \\
\hline 30 & Portugal & 1092 \\
\hline 31 & Belgium & 982 \\
\hline 32 & Finland & 928 \\
\hline 33 & Scotland & 924 \\
\hline 34 & Saudi Arabia & 793 \\
\hline 35 & South Africa & 752 \\
\hline 36 & Austria & 702 \\
\hline 37 & Egypt & 664 \\
\hline 38 & Ireland & 613 \\
\hline 39 & Algeria & 547 \\
\hline
\end{tabular}


Table 9: Comparison of the number of Energy and Fuels articles from South Africa and comparator countries in 2003-2013 according to electricity production (GWH) and population

\begin{tabular}{l|c|c|c}
\hline \multicolumn{1}{c|}{ Country } & $\begin{array}{c}\text { Energy articles } \\
\mathbf{2 0 0 3 - 2 0 1 3}\end{array}$ & $\begin{array}{c}\text { Articles/ } \\
\text { GWH(00) }\end{array}$ & $\begin{array}{c}\text { Articles/ } \\
\text { population } \\
\text { (million) }\end{array}$ \\
\hline South Africa & 752 & 2.9 & 13.9 \\
\hline Brazil & 2078 & 3.7 & 10.2 \\
\hline Russia & 1914 & 1.8 & 13.1 \\
\hline Australia & 3603 & 14.5 & 152.6 \\
\hline Canada & 5316 & 8.3 & 150 \\
\hline New Zealand & 366 & 8.3 & 81 \\
\hline
\end{tabular}

Table 7 shows the countries with which South African researchers collaborate for their research in the field of energy and fuels. USA, France, China and England are the top collaborating countries. It should be noted that Germany is lower down in the list (at 11th) even though it is third in collaborations with South Africa across all disciplines. ${ }^{12}$ It should also be noted that $36.6 \%$ of the disciplinary articles were co-authored with international partners, which is lower than the country's average of $53 \% .{ }^{1}$ It can be argued that the low international collaborative activity in this field is the result of its low research activity in the country, although collaboration in the field has increased from $25 \%$ at the beginning of the period to $31 \%$ at the end of the period.

Table 8 shows the South African ranking according to the number of Energy and Fuels articles produced. South Africa is ranked 35, just above Austria and Egypt.

Table 9 shows the number of publications in the 'energy and fuels' core literature from South Africa and five comparator countries - Australia, Canada, New Zealand, Brazil and Russia - during the more recent period 2009-2013. The comparator countries are those with which South African authorities historically have compared the country.

Only New Zealand produces fewer Energy and Fuels articles than South Africa. In order to normalise the comparison, we estimated the number of energy and fuels publications per million population and per KWh of electricity produced. The two indicators provide evidence of the research that supports the population and the energy sector. Table 9 shows that South Africa compares unfavourably with the five comparator countries in terms of number of publications per KWh and it is half way in terms of articles per million population. It should be noted that South Africa is closer to Brazil and Russia and appears to be weaker than Australia and New Zealand. New Zealand appears to be stronger than South Africa in these comparisons even though it produces fewer research articles than South Africa.

\section{Discussion and conclusion}

A bibliometric assessment was undertaken of energy and fuels research in South Africa for the period 2003-2013. The major findings are summarised as follows:

- The South African national research system is producing a relatively small number of research publications in the international energy core literature. Energy research literature constitutes approximately $1 \%$ of the national output. Comparisons with the field of water research (another multidisciplinary field) support the argument that specified funding for particular research fields has the desirable effect of improving research performance.

- The number of South African energy research publications is following an increasing trend, albeit from a small basis. Furthermore, energy research is distributed across a number of universities with each organisation producing a small number of research articles. The small number of research articles can be interpreted as a small number of relevant researchers. Hence, the move of one or two prolific researchers from one institution to another could drastically change the rankings of the institutions producing energy research. Comparisons with universities abroad indicate that the South African universities should aim to increase fivefold their energy-related publications (as well as their number of researchers in the field) if they wish to be comparable with similar institutions abroad.

- The top five most prolific institutions in the country produce more than $50 \%$ of the country's contribution to core energy and fuels literature. This spread is considered a high dispersion as a number of other scientific disciplines in the country are concentrated in only one or two institutions. It is suggested that political equity considerations in the country spill over in the research domain, which is of particular developmental and science policy importance. Can a country leapfrog its science and innovation system to catch up with the rest of the world and compete internationally through a 'distributed' approach or should it concentrate its limited scientific expertise to a few focused research centres? This issue has been identified as one of the major South African policy challenges by the Organisation for Economic Cooperation and Development in their review of the country's innovation policy. ${ }^{13}$

- Analysis of the specialisation patterns of energy research shows that fossil and renewable energy related research are equally emphasised in the country, albeit by a small number of articles. Topics related to energy efficiency appear to be following an ascending trend.

- Identification of the country's collaborative patterns indicates that energy researchers do not collaborate to the same extent as researchers in other research areas. It is suggested that this is a result of the limited energy research in South Africa.

- International comparisons in terms of articles per GWH of electricity produced and articles per million population show that South Africa should increase substantially its effort in the field in order to be comparable with other similar countries.

Probably the most important finding for policy is the small number of research articles in the field. The discipline's ranking is far below what was expected from a research field with a dedicated agency (Sanedi). Water research, another multidisciplinary field in the country with a dedicated agency, is ranked substantially higher than energy research. The discrepancy can be linked to Sanedi's limited budget. It is also interesting to identify whether the relevant departments are using publication outputs in order to decide priorities and funding.

The lack of independent academic energy research has critical impacts for the planning of energy in the country. In the past, it has been argued ${ }^{8}$ that the inability of Eskom to meet electricity demand could have been prevented if there were independent researchers to argue in favour of additional power capacity. Currently, the lack of expertise in the field affects the research debate related to the need of nuclear energy in the Western Cape and the investigations related to future supply and demand for electricity in the country.

\section{Acknowledgements}

I thank the Department of Science and Technology (South Africa) for financial support for the current investigation.

\section{References}

1. Pouris A, Ho Y-S. Research emphasis and collaboration in Africa Scientometrics. 2014;98:2169-2184. http://dx.doi.org/10.1007/s11192013-1156-8

2. Jacobs $I M$, Pouris $A$, Naidoo D. A scientometric examination of the performance of water research in South Africa. Water SA. 2014;40(4):631637. http://dx.doi.org/10.4314/wsa.v40i4.8

3. Academy of Science of South Africa (ASSAf). The state of energy research in South Africa. Pretoria: ASSAf; 2014. 
4. Vlachy J. World publication output in cross disciplinary physics: Materials science, physical chemistry, energy research, biophysics. Czech J Phys. 1983;33(2):247-250. http://dx.doi.org/10.1007/bf01605505

5. Pouris A, Pouris A. Structure of energy related literature: An application of citation analysis. S Afr J Sci. 1987;83:138-142.

6. Uzun A. National patterns of research output and priorities in renewable energy. Energ Policy. 2002;30(2):131-136. http://dx.doi.org/10.1016/ S0301-4215(01)00084-2

7. Kostoff NR, Tshiteya R, Pfeil MK, Humenik AJ, Karypis G. Power source roadmaps using bibliometrics and database tomography. Energy. 2005;30(5):709-730. http://dx.doi.org/10.1016/j.energy.2004.04.058

8. Pouris A. Energy and fuels research in South African universities: A comparative assessment. Open Inform J. 2008;1:1-9.
9. Bradford SC. Documentation. Washington DC: Public Affairs Press; 1950.

10. Ziegler EB. Methods for bibliometric analysis of research: Renewable energy case study [ME thesis]. Boston, MA: Massachusetts Institute of Technology; 2008.

11. Pouris A. Assessing scientific strengths of academic institutions: The University of Pretoria. S Afr J Sci. 2006;102:23-26.

12. Pouris A. Swiss-SA Joint Research Programme and Germany-SA Science and Technology Cooperation Impact Study. Pretoria: Department of Science and Technology; 2014.

13. Organisation for Economic Cooperation and Development (OECD). Review of South Africa's Innovation Policy. Paris: OECD DSTI/STP; 2007. 